\title{
Monetary Dynamics and Gold Dinar: An Empirical Perspective
}

\author{
MANSOR H. IBRAHIM ${ }^{*}$ \\ Professor of Economics \\ International Islamic University Malaysia, Malaysia \\ E-mail:mansorhi@iiu.edu.my.
}

\begin{abstract}
According to proponents of Gold Dinar particularly Meera and Aziz (2002), termed as Dinarists', the fiat monetary system is inherently unstable. In providing an empirical perspective on this contention, this paper investigates monetary dynamics of a Muslim economy, Malaysia. To this end, the paper adopts a vector autoregressive (VAR) framework to document dynamic interactions between money supply and various macroeconomic variables including real output, price level, interest rate and stock prices. The results seem to provide some support for the Dinarists' contention. First, the results portray clearly an important causal role of money supply for other macroeconomic variables. Second, we document some evidence that expansion in money supply is inflationary. Lastly, money supply - interest rate and money supply - stock price interactions are destabilizing. More importantly, expansion in money supply has the potential of breeding asset price bubbles. However, apart from the above findings, we also find that money supply reacts positively to increase in real output. Since the accommodative role of money supply is necessary or a pre-condition for expansion in production, arguments for Gold Dinar need to be qualified. Moreover, the viability of Gold Dinar comes into question when political and international aspects of monetary standards are considered.
\end{abstract}

\section{Introduction}

The recurring currency and financial problems, with the 1997 Asian and 1998 Russian crises as latest examples, have spurred enormous interest among economists and policymakers on the subject of monetary standards, especially the Gold standard and the current fiat standard. It is argued that the Gold standard, i.e. using gold as a

(*) I would like to thank the referees of the journal for providing helpful comments on the early draft of the paper. I also would like to acknowledge the financial assistance from the Research Center, International Islamic University Malaysia. The usual disclaimer, however, applies. 
medium of exchange or pegging a nation's currency to the fixed price of gold, provides a stable nominal anchor and, thus, ensures price stability. Meanwhile, the current fiat system tends to breed persistent inflation. Various studies have provided support for this argument. For instance, Bordo (1998) notes lower and less variable rate of inflation during the classical gold standard (1881-1913) as compared to the floating period (1971-1989). Kydland and Wynne (2002) reaffirm the long-run price stability during the classical gold standard. Thus, it is not surprising that there is a mention of gold and the Gold Standard every time nations face crises. Yet, despite this benefit of gold, whether gold will make a return as the standard for monetary payment system remains controversial (Bernstein, 2000).

Among especially Muslim economists, a view to return back to Gold Dinar has reemerged and become a topic of debate. At least three justifications have been offered for returning to Gold Dinar. The first justification lies in the belief that Gold Dinar is part of the Islamic faith (Vadillo, 2002). Accordingly, the return to Gold Dinar is a must and can not be questioned. The second reason stresses the importance of reducing dependence on the US dollar as an international currency. Namely, Gold Dinar can provide a viable alternative to the current and dominant US currency. The final justification finds fault with the current fiat and fractional reserve banking system. It is argued that, with the practice of interest rate, the current system is unjust and inherently unstable. The recurring currency and financial turbulence experienced the in recent past is just a manifestation of the major weakness of the system. The foundation to this instability stems from the ability of banks to create money, which allows money supply to grow by default (Meera and Aziz, 2002). Then, through the equation of exchange and given potential output, the growing money supply can generate instability in the economy. Gold Dinar, as it is argued, is free from these weaknesses.

Among these justifications, the last seems to provide grounds for testable implications. The acceptance of the first reason suggests no debate or evaluation of the viability of Gold Dinar. However, whether Gold Dinar is part of the Islamic faith is inconclusive. Haneef and Barakat (2002) review the fiqhi opinion on the use of gold and silver as money. According to them, there are at least two opinions. One opinion views gold and silver as money obligatory, while the other allows flexibility. That is, the latter admits other forms of money. While there is a need to reduce dependence on the US dollar, returning to Gold Dinar is not imperative since there are many other international currencies such as the euro that can play that function. However, according to the third justification, the root cause of economic problems is the continuing increase in money supply facilitated by fiat and fractionally reserve banking system. Money supply is the cause of inflation, asset price bubbles and instability in the economy. In other words, money is a forcing or a causal variable. If true, then the justification for the use of Gold Dinar may have some validity. However, if money supply reacts to accommodate expansion in real activities then Gold Dinar may not be a viable form of money. The reason is that, unlike fiat money, money supply can not be simply increased as needed under the gold standard and it depends crucially on the gold reserves (Bernstein, 1981, Mishkin and Eakins, 2003). Accordingly, it seems understanding monetary dynamics of an economy is essential for the discussion of Gold Dinar as a viable alternative system for monetary arrangement. 
The objective of this study is to provide an empirical perspective on Gold Dinar by evaluating monetary dynamics of a Muslim country, namely Malaysia. In the study, we assess empirically whether money supply is the root cause of instability or it grows to accommodate expansion in real economic activities. In the next section, we present a theoretical foundation, which is based on the quantity theory of money, and empirical framework for assessing monetary dynamics of Malaysia. Then, in section 3, we describe and provide preliminary analyses of the data used. Section 4 presents estimation results of monetary dynamics. Lastly, section 5 summarizes the main findings and their implications.

\subsection{Theoretical Foundation}

\section{Model}

The theoretical link between money supply and other macroeconomic variables such as output and price level can be stated using the quantity theory of money ${ }^{(1)}$. Namely,

$$
M V=P Y
$$

where $M$ is nominal money supply, $V$ is velocity of money, $P$ is price level, and $Y$ is real income. The equation is central to monetarists' argument that money supply is the main factor accounting for economic fluctuations in the short run and the cause of inflation in the long run. According to the quantity theory, velocity of money is fixed or, in its modern restatement, is a stable and predictable function of interest rates. Thus, any changes in money supply lead to changes in nominal income $(P Y)$ in the short run. In the long run, since real income is determined by the supply side of the economy, the increase in money supply is translated to only higher price level. Based on this reasoning together with the premise that economic agents are basically ignorant of the working of economic system, monetarists advocate passive monetary policy and recommend fixed growth of money supply as a way of ensuring monetary stability. Implicit in this recommendation is that monetary authorities can control the level of money supply. By using various monetary policy instruments to ensure a predetermined fixed growth of money supply, price stability and economic stability can be achieved.

Meera and Aziz (2002) rely on the aforementioned monetarists' view to argue that money supply is the root cause of instability. However, they deviate from the monetarists by stating that, with positive interest rate, money supply will grow by default. It seems that, according to their arguments, money supply is uncontrollable in the long run. That is, under fiat, fractional reserve banking and interest rate-based system, money supply has a tendency to expand even if no expansionary policy is attempted. This means that, as velocity and real output are fixed, price level will continuously increase. They go further to argue that, in the fiat system, the government is very likely to intervene in the markets by controlling prices of goods specifically basic food items as a response to the ever-increasing prices. The result of this price control is that the increase in money supply will find its way to other markets especially markets for financial assets, creating asset price bubbles. Then, the destruction of

(1) The simple quantitative theory of money instead of more elaborated models of, for instance, Barro (1979) or Choudhury (2004), is used to be in line with the work of Meera and Aziz (2002). They rely only on the framework for making conclusions against the fiat monetary system. 
money through for example repayments of bank loans can lead to bubble burst and sharp decline in asset prices, setting the stage for recession. Additionally, the fiat money interest rate system is subject to speculative and manipulative activities. Based on these characteristics of the current fiat money, Meera and Aziz (2002) advocate the use of Gold Dinar as an alternative currency, the establishment of fully-reserve banking system and interest-free economy. According to them, Gold Dinar ensures price stability since its supply can not grow by default and it is not destructible. Moreover, unlike the fiat system, Gold Dinar is absent from speculative elements. Henceforth, we refer to the Meera and Aziz's view as Dinarists' view of the fiat system.

Indeed, we can delineate various causal patterns that are in line with Dinarists. These causal patterns involve interactions between money supply, price level, output and other asset prices. These can be stated in the following three causal relations ${ }^{(2)}$ :

$$
\begin{aligned}
& \uparrow M \rightarrow \uparrow P, \\
& \uparrow M \leftrightarrow \downarrow r, \\
& \uparrow M \leftrightarrow \uparrow \mathrm{A},
\end{aligned}
$$

In the above notations, $\mathrm{M}$ is money supply, $\mathrm{P}$ is price level, $\mathrm{r}$ is interest rate, and $\mathrm{A}$ is asset prices. The sign $\uparrow$ means increase, $\downarrow$ means decrease, $\rightarrow$ means affects, and $\leftrightarrow$ means affects and is affected by.

According to Dinarists, as stated in (a), there is a causal relation that runs from money supply to price level. For the case of real output, the causal pattern from money to output is not clear. While they refer to the quantity theory of money with fullemployment level of output in their arguments, they acknowledge that recession can be triggered by monetary contraction (see below). Then, since money supply can grow by default, there should be no causal relation that runs from real output to money supply or even from the price level to money supply ${ }^{(3)}$. It should be noted that, while Meera and Aziz (2002) accepts the monetarists' proposition that inflation is a monetary phenomenon, the negation of (a) is not inconsistent with their view. According to them, the causal relation may not emerge if the government intervenes by controlling prices.

The destabilizing effect of changes in money supply may be represented by (b) and (c). As stated in Meera and Aziz (2002), the continually increasing money supply will result in interest rate reduction after full-employment level of output being achieved. Then, as long as the interest rate remains positive, money supply will keep on increasing, in their words, by default. Moreover, the reduction in interest rate further encourages lending activities of the banks. As bank loans expand, so does money supply. Accordingly, although the former mechanism suggests a default increase in money supply given positive interest rate, the latter clearly suggests feedback causality from interest rate to money supply. Notably, this feedback causality is destabilizing.

(2) It is admitted that more than these three causal relations are stated in Meera and Aziz (2002). We believe that these three relations are sufficient and capture the essence of Dinarists. Moreover, other causal relations are at best vague and should not be used as bases for testable implications. Please refer to Meera and Aziz (2002) for details.

(3) This is drawn from the repeating statement that money supply under the fiat system can grow on its own in the long run as long as interest rate is positive. Thus, the growth of money supply is unlikely to be accommodative. 
The increase in money supply leads to a reduction in interest rate. This leads to further expansion of money supply. As stated in (a), there will be continuous pressure on the price level. Since prices of certain essential items are controlled, the increase in money supply will generate asset price bubbles as stated in (c), highlighting the second source of instability. Speculative activities are promoted prompting more money supply creation through bank lending to capitalize on expected increase in asset prices. But then, when bank loans contract, asset price bubble will burst and interest rate will increase culminating in economic recessions. The downturn is aggravated by monetary contraction through crises in markets for financial assets.

Underlying these causal relations is the fact that Dinarists view fluctuations in money supply as the main cause of fluctuations in other variables ${ }^{(4)}$. Stated differently in a more formal way, fluctuations in such variables as real output (especially the downturn), price level, interest rate, and asset prices are accounted in most part by variations in money supply, making the money supply a forcing or main causal variable. Then, if there are feedback relations from especially interest rate and stock prices to money supply, the patterns are destabilizing. However, if the patterns are stabilizing suggesting the presence of monetary authorities' reaction function, e.g. reduction in money supply to counter interest rate decline or asset price increase, the arguments put forth by Dinarists are weakened. Moreover, in no place in their work, Meera and Aziz (2002) mention the causal feedback from real output to money supply. Indeed, the presence of causal relations from real output to money supply can greatly weaken the Dinarists proposition that "everything is due to the fiat monetary system." More specifically, if money supply reacts to accommodate the expansion in real activities then Gold Dinar may be less viable. The reason is that, unlike fiat money, gold can not be simply increased as needed. The "inflexibility" of gold to adjust to output expansion arising from other sources such as productivity shocks may not facilitate output expansion in the first place.

\subsection{Empirical Model}

The foregoing theoretical link between money supply and other macroeconomic variables suggest the importance of looking at monetary dynamics as a way to assess the viability of Gold Dinar. To begin, we first look at the variables' stochastic properties. The presence of stochastic trend in money supply and the absence of cointegration between money supply and other variables can be interpreted as, in the long run, money supply will grow by default. Regardless of whether money supply is cointegrated or not cointegrated with other variables, the argument for Gold Dinar will be strengthened if money supply is the source of fluctuations in other variables and the causal patterns are destabilizing, as argued above. In assessing these, it seems natural to apply vector autoregressive (VAR) approach preceded by unit root and cointegration tests. The framework captures the empirical regularities in the data and thus provides information on the causal nexus among variables.

A VAR model is specified as follows:

(4) In this aspect, Dinarists share a similar view with monetarists. However, the Dinarists differ from the monetarists in their view that money supply is uncontrollable. Meanwhile, suggesting a constant money growth rule, monetarists note the controllability of money supply. 


$$
X_{t}=A_{0}+\sum_{k=1}^{p} A_{k} X_{t-k}+e_{t}
$$

where $X_{t}$ is an $\mathrm{n} \times 1$ vector of variables, $A_{0}$ is an $\mathrm{n} \times 1$ vector of constant terms, $A_{k}$ is an $\mathrm{n} \times \mathrm{n}$ matrix of coefficients, $e_{t}$ is an $\mathrm{n} \times 1$ vector of error terms, and $p$ is the order of autoregression. The interpretation of model (2) is normally based on its moving average representation. By inverting or successive substitution, VAR model (2) has a moving average representation as follows:

$$
X_{t}=B+\sum_{k=0}^{\infty} B_{k} e_{t-k}
$$

Thus, $X_{t}$ is expressed as a linear combination of current and past innovations. Based on (3), variance decompositions and impulse-response functions are simulated to assess dynamic causal relations between money supply and other macroeconomic variables. Basically, variance decompositions capture the proportion of the forecast error variance of a variable of interest attributed to innovations in other variables. Accordingly, it serves as a natural measure of relative importance of various shocks to the variable of interest. Meanwhile, impulse-response functions trace the response of a variable to innovations in other variables in the system. From the impulse response functions, we can establish both the magnitude as well as the direction of responses of the variable. These statistics, thus, are central to our analysis.

We precede VAR estimation with unit root and cointegration tests. Briefly stated, a variable is said to be integrated of order $d$, written $\mathrm{I}(d)$ if it requires differencing $d$ times to achieve stationarity. Any variable that is integrated of order 1 or higher is nonstationary. Then, a set of variables is said to be cointegrated if they are non-stationary integrated of the same order and yet their linear combination is stationary. The evidence for cointegration suggests that they can not drift farther away from each other arbitrarily. Any deviations of a variable from the long run relationship will result in some variables adjusting to return back to the long run path; that is, the deviations (or disequilibrium) will be corrected. Accordingly, results from cointegration test not only provide information on the long run relationship among the variables but also are crucial for proper specification of their short run dynamics as represented by the above VAR model. In particular, the findings that the variables are non-stationary and are not cointegrated suggest the use of VAR model in first differences. However, if they are cointegrated, a vector error correction model or a level VAR model can be used (Engle and Granger, 1987, Selover and Round, 1996).

We apply the commonly used augmented Dickey-Fuller (ADF) and Phillips-Perron (PP) unit root tests for determining the variables' orders of integration. To test for cointegration, we employ a VAR-based approach of Johansen (1988) and Johansen and Juselius (1990). Roughly, the JJ test for cointegration is based on evaluating the rank of coefficient matrix of level variables in the regression of changes in a vector of variables on its own lags and lagged level variables. The rank of the matrix, which depends on the number of its characteristic roots (eigenvalue) that differ from zero, indicates the number of cointegrating vectors governing the relationships among variables. Johansen (1988) and Johansen and Juselius (1990) develop two test statistics to determine the number of cointegrating vectors - the trace and the maximal eigenvalue statistics: 


$$
\begin{aligned}
& \lambda_{\text {Trace }}=-T \sum_{i=r+1}^{k} \ln \left(1-\lambda_{i}\right) \\
& \lambda_{\text {Max }}=-T \ln \left(1-\lambda_{r+1}\right)
\end{aligned}
$$

where $T$ is the number of effective observations and $\lambda$ s are estimated eigenvalues. The trace statistics tests the null hypothesis that there are at most $r$ cointegrating vectors against a general alternative. Meanwhile, the maximal eigenvalue test is based on the null hypothesis that the number of cointegrating vectors is $r$ against the alternative hypothesis that it is $r+1$.

In a nutshell, the empirical method of the present study consists of the following steps. First, we evaluate unit root and cointegration properties of the variables. Then, we estimate a VAR model, from which we assess causal nexus among the variables concerned. More specifically, we simulate variance decompositions and impulseresponse functions as a basis for causal inferences.

\section{Data Preliminaries}

In assessing Malaysian monetary dynamics, we utilize a 5-variable VAR model consisting of money supply, real output, price level, interest rate, and stock prices. We use M1 monetary aggregate as a measure of money supply (LM1). Meanwhile, real output and price level are represented respectively by real gross domestic products (LGDP) and consumer price index (LCPI). We employ three-month Treasury bill rate to represent the interest rate (TB3) and the Kuala Lumpur Composite Index (LKLCI) to represent stock prices. The main sources of data are Bank Negara's Monthly Statistical Bulletin (various issues) and IMF's International Financial Statistics, CD-Rom version. Except the interest rate, all data are expressed in natural logarithm. The data are quarterly covering the period 1978.Q1 to 2003.Q4. To avoid the potential confounding effects of 1997/1998 Asian crisis, we also examine dynamic interactions among the five variables using the shortened sample, namely 1978.Q1 - 1997.Q2.

Before we proceed, we first subject each variable to ADF and PP unit root tests and Johansen-Juselius cointegration test ${ }^{(5)}$. The results of the tests are presented in Table 1 and Table 2 respectively. As may be observed from the Table, the two tests indicate that all variables except LCPI are non-stationary in level but become stationary after first differencing. That is, they are integrated of order 1 , or I(1). In the case of LCPI, however, we find conflicting results. Namely, while it is stationary in level under the ADF test, it belongs to I(1) process under the PP test. These conflicting results motivate us to further assess its stochastic property by plotting its correlogram. We find that the correlogram of LCPI is gradually declining, which suggests non-stationarity in level. Accordingly, like other variables, we also treat LCPI as an I(1) process. Given results of the unit root tests, we proceed to cointegration test. The lag length of the test is set to 5, which we find sufficient to render the error terms serially uncorrelated. The results of the test are given in Table 2. From the test, we find evidence of cointegration among the variables based on the trace statistics. More specifically, the test suggests a unique cointegrating vector that ties these variables together in the long run.

(5) In view of better performance of the tests for longer time span, the tests are applied only to the full sample. However, it is pleasing to note that the results are similar using the shortened sample. 
TABLE 1. ADF and PP unit root tests.

\begin{tabular}{|l|l|l|l|l|}
\hline & ADF Test & \multicolumn{2}{l|}{ PP Test } & $\Delta \mathrm{X}$ \\
\hline Variables & $\mathrm{X}$ & $\Delta \mathrm{X}$ & $\mathrm{X}$ & $-9.821^{*}$ \\
\hline LM1 & -2.301 & $-4.892^{*}$ & -2.070 & $-8.400^{*}$ \\
\hline LM2 & -3.137 & -2.502 & -1.628 & $-7.442^{*}$ \\
\hline LM3 & -1.746 & -2.408 & -1.251 & $-11.20^{*}$ \\
\hline LGDP & -1.579 & $-4.369^{*}$ & -3.384 & $-8.454^{*}$ \\
\hline LCPI & $-3.869^{* *}$ & -3.086 & -2.062 & $-9.587^{*}$ \\
\hline TB3 & -1.942 & $-6.131^{*}$ & -1.852 & $-10.98^{*}$ \\
\hline LKLCI & -2.480 & $-6.979^{*}$ & -2.833 & \\
\hline
\end{tabular}

Note: $*$, and $* *$ denote significance at $1 \%$ and $5 \%$ levels respectively.

TABLE 2. Cointegration test - basic system.

\begin{tabular}{|l|c|c|c|c|}
\hline Null & \multicolumn{2}{|c|}{ Test Statistics } & \multicolumn{2}{c|}{ Critical Values (5\%) } \\
\hline Hypothesis & Trace & Max & Trace & Max \\
\hline $\mathrm{r}=0$ & 78.89 & 32.25 & 68.52 & 33.46 \\
\hline $\mathrm{r} \leq 1$ & 46.64 & 22.40 & 47.21 & 27.07 \\
\hline $\mathrm{r} \leq 2$ & 24.24 & 13.45 & 29.68 & 20.97 \\
\hline $\mathrm{r} \leq 3$ & 10.78 & 9.79 & 15.41 & 14.07 \\
\hline $\mathrm{r} \leq 4$ & 0.99 & 0.99 & 3.76 & 3.76 \\
\hline
\end{tabular}

Note: the basic system uses LM1 as a measure of money supply and full sample period (1978.Q1 - 2003.Q4).

The unit root and cointegration results that we obtain provide no clear cut evidence supportive of the Dinarists' views. While M1 money supply tends to have stochastic trend or is not mean reverting, its long-run movements are tied to other variables. This means that their dynamic causal interactions need to be assessed, which we now turn to.

\subsection{Results}

\section{Results and Discussion}

The VAR system consisting of LGDP, LCPI, TB3, LM1 and LKLCI is estimated using the full sample, i.e. 1978.Q1-2003.Q4. The lag order of VAR is chosen such that the error terms are serially uncorrelated. From the estimated VAR, we simulate variance decompositions and impulse response functions. We adopt Sims' (1980) empirical strategy to identify various shocks using the so-called Cholesky factorization. As it is well-known, the results from such a strategy depend principally on the causal orderings of variables in the system unless the contemporaneous correlations among error terms are low. Normally, the variables that are most exogenous are placed first in the ordering followed by the variables that are less exogenous (or more endogenous). In other words, the variables higher in the ordering are assumed to respond contemporaneously to the variables placed before them. By contrast, the variables entered first react with lags to the variables higher in the ordering. In the analysis, we order the variables according to the following order: LGDP, LCPI, TB3, LM1 and LKLCI. Reasonably, real output and consumer prices are sluggish to adjust to shocks in other variables and thus are considered most exogenous in the system. Meanwhile, reflecting investors' expectations, the stock prices tend to be most endogenous. 
Table 3 presents variance decompositions at various horizons of each variable. Meanwhile, Fig. 1 graphs the responses of money supply to other variables in the system and vise versa ${ }^{(6)}$. Various interesting results may be observed from the table. Looking first at the interactions between M1 money supply and other macroeconomic variables, the main focus of the present paper, we find evidence suggesting the significant role of M1 money supply in accounting for variations in other variables. More specifically, more than $20 \%$ of LGDP forecast error variance is attributable to innovations in money supply at 4-quarter to 8-quarter horizons. However, this percentage declines to $14.7 \%$ after 12 -quarter horizon and to only $7.4 \%$ after 20 -quarter horizon. The result, thus, accords well with conventional theories that shocks in money supply have effects on real output in the short run. However, in the long run, the real effects of money supply tend to go to zero. The response function of LGDP to LM1, plotted in Fig.1, further substantiates this observation. Note that the significant responses of LGDP to LM1 innovations last for about 7 quarters.

TABLE 3. Variance decompositions - full sample.

\begin{tabular}{|c|c|c|c|c|c|}
\hline & \multicolumn{5}{|c|}{ Explained by variations in } \\
\hline Horizons & LM1 & LGDP & LCPI & TB3 & LKLCI \\
\hline \multicolumn{6}{|c|}{ (a) Variance Decomposition of LMI } \\
\hline 1 & 82.34 & 10.16 & 1.97 & 5.52 & 0.00 \\
\hline 4 & 66.82 & 20.46 & 2.74 & 4.53 & 5.46 \\
\hline 8 & 54.61 & 34.80 & 2.43 & 2.46 & 5.70 \\
\hline 12 & 41.16 & 46.92 & 3.82 & 1.91 & 6.18 \\
\hline 20 & 21.68 & 68.34 & 2.52 & 1.55 & 5.91 \\
\hline \multicolumn{6}{|c|}{ (b) Variance Decomposition of LGDP } \\
\hline 1 & 0.00 & 100.00 & 0.00 & 0.00 & 0.00 \\
\hline 4 & 21.97 & 70.46 & 0.24 & 0.16 & 7.18 \\
\hline 8 & 21.31 & 69.54 & 0.68 & 0.38 & 8.09 \\
\hline 12 & 14.70 & 74.76 & 2.46 & 0.65 & 7.43 \\
\hline 20 & 7.38 & 81.35 & 2.42 & 1.13 & 7.72 \\
\hline \multicolumn{6}{|c|}{ (c) Variance Decomposition of LCPI } \\
\hline 1 & 0.00 & 1.24 & 98.76 & 0.00 & 0.00 \\
\hline 4 & 0.79 & 6.58 & 90.05 & 1.57 & 1.00 \\
\hline 8 & 3.37 & 6.80 & 86.72 & 1.86 & 1.25 \\
\hline 12 & 8.89 & 24.64 & 61.76 & 2.38 & 2.32 \\
\hline 20 & 7.35 & 63.81 & 23.07 & 1.44 & 4.33 \\
\hline \multicolumn{6}{|c|}{ (d) Variance Decomposition of TB3 } \\
\hline 1 & 0.00 & 10.83 & 2.52 & 86.65 & 0.00 \\
\hline 4 & 10.00 & 11.06 & 10.06 & 67.69 & 1.19 \\
\hline 8 & 11.10 & 30.03 & 6.23 & 45.91 & 6.72 \\
\hline 12 & 18.39 & 38.53 & 3.71 & 27.70 & 11.66 \\
\hline 20 & 17.11 & 40.96 & 4.20 & 22.48 & 15.25 \\
\hline \multicolumn{6}{|c|}{ (e) Variance Decomposition of LKLCI } \\
\hline 1 & 23.02 & 0.12 & 0.65 & 9.40 & 66.81 \\
\hline 4 & 33.92 & 15.56 & 0.35 & 4.64 & 45.52 \\
\hline 8 & 32.54 & 29.40 & 0.70 & 3.51 & 33.85 \\
\hline 12 & 28.92 & 32.95 & 2.27 & 3.02 & 32.84 \\
\hline 20 & 21.41 & 46.86 & 1.86 & 3.03 & 26.84 \\
\hline
\end{tabular}

(6) To conserve space, we report only impulse responses between LM1 and other macroeconomic variables (i.e. LGDP, LCPI, TB3 and LKLCI). The impulse responses of other macroeconomic variables are available upon request from the author. 

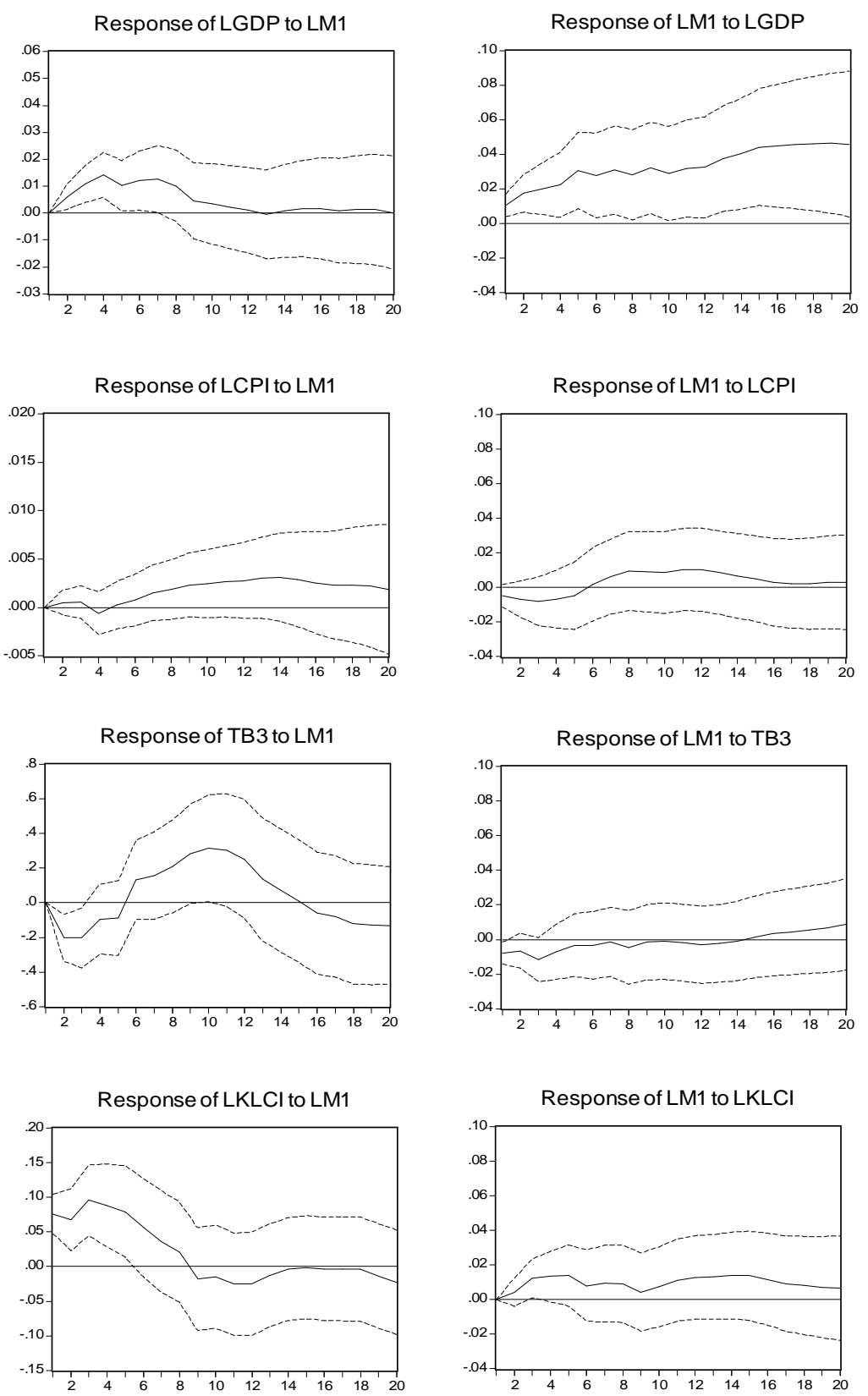

FIG. 1. Impulse response functions - full sample. 
While innovations in M1 money supply do not seem to account for the variations in LCPI, the M1 money supply explain significant proportions of TB3 and LKLCI forecast error variances. Roughly, $18 \%$ of the variations in TB3 is accounted by changes in M1 money supply at 12-quarter to 20-quarter horizons. Meanwhile, the influences of M1 innovations on LKLCI are immediate, accounting for $23 \%$ of the LKLCI variations after 1-quarter and increase to more than $30 \%$ after 1 to 2 years. Indeed, in the case of LKLCI, M1 shocks remain important even after 20 quarters or 5 years. From the impulse-response functions, we note insignificant response of LCPI to shocks in M1 money supply. Meanwhile, TB3 declines initially and then increases in responses to innovations in M1 money supply. Thus, in line with the liquidity effect of monetary policy, expansion in money supply leads to a decline in interest rate. Then, consistent with the loanable fund framework, the subsequent expansionary effect of money supply on real output places upward pressures on interest rate (Mishkin, 1997, pp. 117-118). Lastly, we may also note from the impulse response functions that LKLCI reacts significantly and positively to shocks in LM1. Thus, given the insignificant responses of LCPI, expansion in M1 money supply seems to find its ways to equity markets.

The variance decompositions also indicate that variations in M1 money supply are explained significantly by shocks in other variables particularly real output (LGDP). Indeed, as horizons increase, the percentage of LM1 forecast error variance attributed to LGDP innovations increases, namely, from $10 \%$ after 1 -quarter to $34.8 \%$ after 8 -quarter and to $68 \%$ after 20 quarters. The impulse response function of LM1 to LGDP innovations reaffirms the significant role of LGDP innovations. In responses to output shocks, M1 money supply reacts positively and significantly. We may also note from the impulse response functions that LM1 reacts significantly to TB3 and LKLCI at short horizons. It seems that LM1 declines in reaction to the increase in TB3 and increases in response to positive shocks in LKLCI. Lastly, it deserves mentioning that shocks in LGDP also explain substantially the forecast error variances of LCPI, TB3 and LKLCI.

We also estimate a VAR model using the shortened sample, i.e. 1978.Q1-1997.Q2, to avoid the potential confounding influences of 1997/1998 Asian crisis and, at the same time, serve as a robustness check for the above results. Variance decompositions and impulse response functions generated from the estimated VAR are presented in respectively table 4 and Fig. 2. Generally, the results conform well to those obtained from the full sample. In line with the previous results, innovations in M1 money supply play a significant role in accounting for variations in real output, interest rate and stock prices. Additionally, from the shortened sample, the percentage of LCPI forecast error variance attributable to shocks in money supply is substantial. Namely, after 20-quarter horizon, shocks in LM1 explain roughly $29 \%$ of the fluctuations in LCPI. The impulseresponse functions, plotted in Fig. 2, indicate positive and significant reactions of LGDP, LCPI, and LKLCI to monetary expansion. Meanwhile, as should be expected, the interest rate declines in response to positive shocks in M1. Likewise, M1 money supply does not seem to be exogenous. As may be noted from Table 4, significant proportion of the variations in M1 is explained by positive shocks in real output. The impulse-response function of LM1 to shocks in LGDP suggests persistent increase in M1 after real output expansion. In this shortened sample, however, the evidence for the responses of M1 to financial variables, i.e. interest rate and stock prices, is less clear cut. 
TABLE 4. Variance decompositions - shortened sample.

\begin{tabular}{|c|c|c|c|c|c|}
\hline & \multicolumn{5}{|c|}{ Explained by variations in } \\
\hline Horizons & LM1 & LGDP & LCPI & TB3 & LKLCI \\
\hline \multicolumn{6}{|c|}{ (a) Variance Decomposition of LMI } \\
\hline 1 & 93.55 & 0.03 & 0.02 & 6.40 & 0.00 \\
\hline 4 & 91.67 & 1.45 & 0.69 & 5.61 & 0.58 \\
\hline 8 & 79.80 & 15.26 & 1.32 & 3.06 & 0.57 \\
\hline 12 & 57.87 & 38.21 & 1.37 & 2.18 & 0.37 \\
\hline 20 & 30.63 & 64.66 & 0.85 & 3.03 & 0.82 \\
\hline \multicolumn{6}{|c|}{ (b) Variance Decomposition of LGDP } \\
\hline 1 & 0.00 & 100.00 & 0.00 & 0.00 & 0.00 \\
\hline 4 & 23.58 & 68.93 & 4.55 & 2.54 & 0.39 \\
\hline 8 & 29.69 & 64.56 & 4.31 & 1.22 & 0.23 \\
\hline 12 & 24.58 & 70.73 & 3.41 & 1.13 & 0.14 \\
\hline 20 & 13.42 & 81.72 & 1.73 & 2.54 & 0.59 \\
\hline \multicolumn{6}{|c|}{ (c) Variance Decomposition of LCPI } \\
\hline 1 & 0.00 & 0.85 & 99.14 & 0.00 & 0.00 \\
\hline 4 & 8.90 & 6.65 & 79.54 & 1.50 & 3.40 \\
\hline 8 & 15.96 & 3.07 & 68.87 & 3.86 & 8.24 \\
\hline 12 & 25.34 & 2.80 & 59.77 & 3.42 & 8.66 \\
\hline 20 & 29.57 & 16.60 & 44.68 & 2.81 & 6.35 \\
\hline \multicolumn{6}{|c|}{ (d) Variance Decomposition of TB3 } \\
\hline 1 & 0.00 & 1.64 & 1.07 & 97.29 & 0.00 \\
\hline 4 & 5.25 & 4.53 & 2.91 & 85.88 & 1.43 \\
\hline 8 & 5.65 & 4.49 & 4.20 & 79.11 & 6.55 \\
\hline 12 & 8.54 & 4.30 & 4.46 & 75.84 & 6.85 \\
\hline 20 & 9.99 & 6.88 & 4.76 & 71.73 & 6.62 \\
\hline \multicolumn{6}{|c|}{ (e) Variance Decomposition of LKLCI } \\
\hline 1 & 33.07 & 8.65 & 6.79 & 0.00 & 51.48 \\
\hline 4 & 41.28 & 5.43 & 14.34 & 2.64 & 36.31 \\
\hline 8 & 48.11 & 6.33 & 13.15 & 3.06 & 29.35 \\
\hline 12 & 44.62 & 13.20 & 11.84 & 3.66 & 26.68 \\
\hline 20 & 36.48 & 26.02 & 10.46 & 4.67 & 22.37 \\
\hline
\end{tabular}

We note above that M1 is not mean-reverting or is non-stationary. Further, the evidence for the presence of cointegration between M1 and other variables suggest that their movements are tied together by a cointegrating vector that specifies the long run relationship among them. Accordingly, in addition to the above noted dynamics as suggested by the VAR models, it is of enormous interest to see which variables adjust to correct for deviations from the long run relationship. To this end, we estimate vector error correction models (VECM). The cointegrating vector, or the error correction term, entering in the VECM is normalized on the M1 money supply. To our interest, for M1 to play a role of disequilibrium adjustment, the error correction term coefficient must be significantly negative. If this is the case, excess money supply (i.e. over the amount justified by other macroeconomic variables) results in monetary contraction. In other words, since it corrects itself, monetary expansion needs not be destabilizing in the long run. 
Response of LGDP to LM1

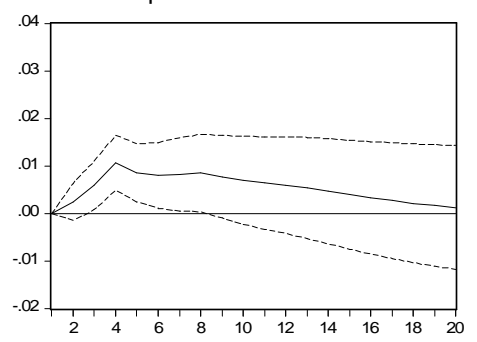

Response of LCPI to LM1

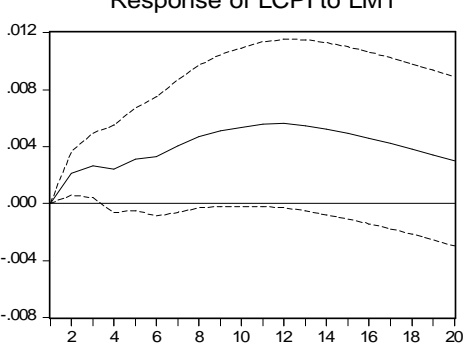

Response of TB3 to LM1

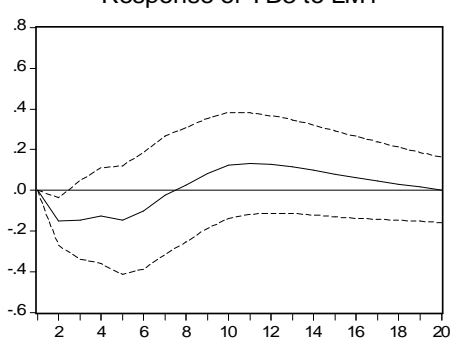

Response of LKLCI to LM1

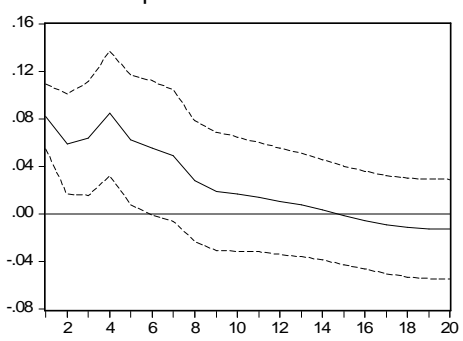

Response of LM1 to LGDP

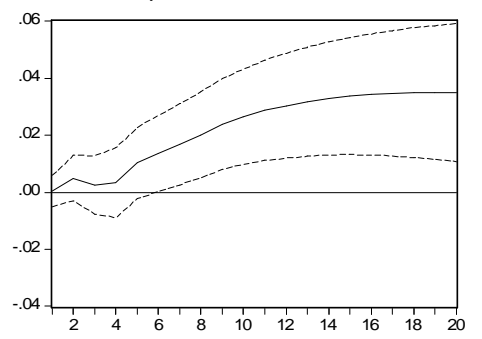

Response of LM1 to LCPI

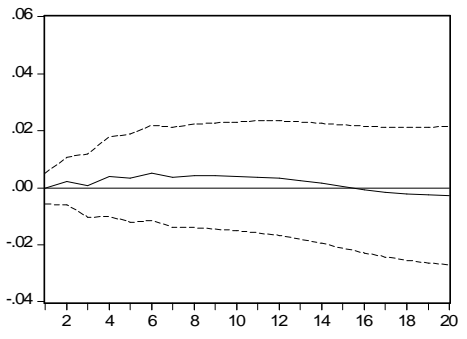

Response of LM1 to TB3

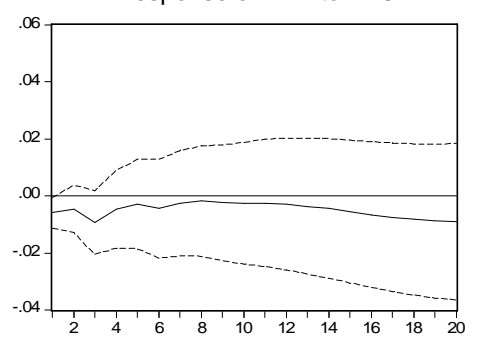

Response of LM1 to LKLCI

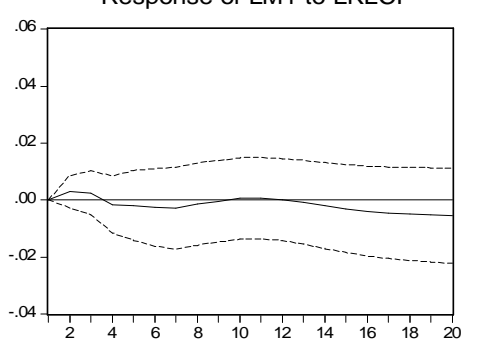

FIG. 2. Impulse response functions - shortened sample. 
The coefficients of the error correction terms from the VECM together with some other statistics for both full sample and shortened sample are presented in Table 5. Interestingly, the error correction term of M1 equation is not significant. This means that M1 money supply is weakly exogenous in the system in that deviations from the long run equilibrium will not be corrected by changes in money supply. Note that the error correction coefficients in price and stock price equations are significant. Interestingly, regardless of the sample used, the coefficient of the error correction term in stock prices equation is positive. This means that, in the long run, excessive money supply is translated into higher stock prices. In the case of the price level, the sign of the coefficient is perverse, being positive for the full sample and negative for the shortened sample.

TABLE 5. Coefficients of error correction terms.

\begin{tabular}{|l|c|c|c|c|}
\hline & Coefficients & & & \\
\hline Equation & Of ECT & R-Square & LB(4) & LB(12) \\
\hline \multicolumn{2}{|c|}{ (a) Full Sample (1978.Q1 - 2003.Q4) } & & \\
\hline$\Delta$ LM1 & $0.011(0.77)$ & 0.571 & 0.6189 & 8.454 \\
\hline$\Delta$ LGDP & $-0.008(1.13)$ & 0.847 & 1.496 & 2.299 \\
\hline$\Delta$ LCPI & $0.008(4.06)^{*}$ & 0.702 & 4.760 & 11.50 \\
\hline$\Delta$ TB3 & $-0.168(0.71)$ & 0.446 & 2.726 & 15.30 \\
\hline$\Delta$ LKLCI & $0.214(3.19)^{*}$ & 0.401 & 2.350 & 10.21 \\
\hline \multicolumn{5}{|l}{} \\
(b) Shortened Sample (1978.Q1 $1997 . \mathrm{Q} 2)$ & & \\
\hline$\Delta$ LM1 & $0.024(0.415)$ & 0.579 & 1.374 & 2.482 \\
\hline$\Delta$ LGDP & $0.022(0.622)$ & 0.876 & 2.642 & 8.862 \\
\hline$\Delta$ LCPI & $-0.037(2.67)^{*}$ & 0.568 & 1.154 & 8.405 \\
\hline$\Delta$ TB3 & $-0.957(0.89)$ & 0.380 & 1.246 & 15.39 \\
\hline$\Delta$ LKLCI & $1.138(3.34)^{*}$ & 0.341 & 1.012 & 5.789 \\
\hline
\end{tabular}

Note: Numbers in parentheses are absolute values of t-ratios. LB is Ljung-Box-Pierce for serial correlation. $*, * *$, and $* * *$ denote significance at $1 \%, 5 \%$, and $10 \%$ respectively.

\subsection{Discussion}

The documented monetary dynamics provide interesting perspectives on Dinarists' contention of the fiat monetary system. Overall, it seems that concerns raised by Dinarists are well grounded empirically. The results clearly portray an important causal role of money supply in explaining fluctuations in other macroeconomic variables regardless of whether the turbulent period of 1997/1998 is incorporated in the analysis. We find some evidence that monetary expansion is inflationary and, more importantly, seems to find its way to asset markets which is in our context, the stock market. Thus, monetary expansion has the potential of breading asset price bubbles as argued by Dinarists. Dynamically, stock prices increase in response to expansion in money supply. Moreover, even if we find evidence for cointegration among the variables under consideration, money supply does not take the role of correcting for deviations from the long run equilibrium path. This is worrisome as excessive changes in money supply will not be self-corrected through its reverse adjustment to the equilibrium. Instead, the excessive money supply is translated into higher stock prices in the long run.

Our results also provide some support for the Dinarists' conjecture that changes in money supply is destabilizing, which seems to be apparent when the full sample is used. 
More specifically, in line with the liquidity effect of monetary policy, expansion in money supply leads to a reduction in the interest rate. Then, a reduction in interest rate leads to further expansion in money supply. Similarly, positive shocks in money supply move the market upwards. Then, stock market increase feeds back to further increase in money supply. This latter finding conforms well to casual observations during the stock market boom of early 1990s. Namely, during the period, loans for portfolio investments increased substantially as investors tried to capitalize on the bullish market.

Do these results suggest unequivocally that the fiat monetary system is inherently unstable and should be abandoned? Or, to place within the Dinarists' perspective, do they provide undivided support for returning to Gold Dinar? While we believe that the Dinarists' views on the fiat system should be embraced seriously, it seems premature to wholeheartedly adopt the Gold Dinar without addressing inherent weaknesses of the Gold Dinar and the viability of its implementation in highly integrated global markets. We document evidence that money supply accommodates expansion in real activities. This is important to facilitate bigger transactions. However, Gold Dinar may not have this ability as it cannot expand or contract as needed. Indeed, the increase in money supply under the gold standard depends crucially on the increase in gold reserves. This makes monetary policy to be influenced by the production of gold and gold discoveries. The peril is that, when money supply did not accommodate output expansion, deflation was the result, as observed during 1870s and 1880s (Mishkin and Eakins, 2003, p. 348). Given rising real wages, unemployment, decrease in production and poverty ensue ${ }^{(7)}$.

Meera and Aziz (2002) are right in stating that output contraction has a monetary origin. However, to limit the contraction episode to only the fiat period is rather incorrect. Indeed, recurring monetary crises were part of the Gold standard (Berstein, 1981). In line with the inflexibility of money supply under the gold standard, the crises during the classical gold standard occurred at the peak of the business cycle when currency or money needs could no longer be met. The inability to accommodate output expansion led to falling prices and increasing interest rate and, finally, crises. Since adherence to the gold standard requires fixed exchange rate, crises or adverse shocks were then transmitted from one country to another. Indeed, there is a consensus view that the gold standard played a major cause of the Great Depression 1929-1933 and there is conclusive evidence that the countries that left the gold standard early suffered less (Bordo et al., 2002 and references therein). Contradicting Meera and Aziz (2002), monetary contraction seems to have more adverse effects under the gold standard than under the gold system.

Moreover, while we note that money supply has a stochastic trend and does not play the role of disequilibrium adjustment, it does not imply that money supply is uncontrollable. Indeed, there are various studies supporting the ability of monetary authorities to control the stock of money supply through the use of monetary instruments or to institute rules that support monetary stability. Thus, with the strong link between money supply growth and inflation, the monetary authorities can ensure monetary stability. Indeed, the various mechanisms and rules that have been adopted by many nations such as European Monetary Union, currency board, or inflation targeting

(7) We thank an anonymous referee of the journal for suggesting this important point. 
are attempts made to ensure price stability. In other words, the main issue seems not to be the forms of monetary standards but the choice between rules and discretion. The gold standard contains a set of credible rules to ensure price stability but at the expense of discretion, which might be needed during the time of crisis. By contrast, the monetary policy under the fiat system as practiced suffers from time inconsistency problem due to discretionary power given to the monetary authority. The issue is thus on how to design set of rules within the fiat system that can alleviate time-inconsistency problems. Monetary union is one of such attempts that has come close to solving the problem (Kydland and Wynne, 2002).

Lastly, the viability of the Gold dinar also comes under serious doubt when viewed from a political perspective, which is not touched by Meera and Aziz (2002) and is not captured by the quantity theory of money. As noted, adherence to the gold standard means that the monetary authority must commit itself to maintain convertibility. Thus, the monetary authority loses its monetary stabilization policies, an option that no nation seems to have political wills. In sum, the appeal to go back to the Gold Dinar seems to lack credence. Indeed, Berstein (2000) correctly notes: "Gold may again serve as the ultimate hedge in chaotic conditions. Its return to its traditional role as universal money is unlikely, however, unless the time should come when the dollar, the euro, and the yen have all failed to function as acceptable means of payments across international borders (p. 372)."

\section{Conclusion}

The paper assesses empirically the contention that, under fiat monetary system, money supply is the root cause of instability. More specifically, we seek to ascertain whether money supply plays a significant causal role for fluctuations in other variables including real output, price level, interest rate and stock prices. Additionally, the directional influences of monetary expansion are also evaluated to see whether money supply increase is expansionary and whether money supply - interest rate and money supply - stock prices interactions are destabilizing. Lastly, we establish whether money supply react to accommodate expansion in output and to correct for disequilibrium. To this end, we estimate VAR models as well as vector error correction models to document empirical regularities contained in the data and their long run adjustments.

Overall, the concerns of Dinarists regarding instability effect of money supply are well grounded empirically. The variance decompositions clearly suggest significant explanatory power of money supply in explaining variations in other variables. Moreover, the impulse response functions provide some evidence that monetary expansion is inflationary. Moreover, it has the potential of generating bubbles in the asset prices, as represented by stock prices. The interactions between money supply and asset prices such as interest rate and stock prices are also destabilizing. Namely, an increase in money supply seems to raise stock prices, which is then fed back to further increase in money supply. Lastly, given deviations from the long-run level, money supply does not correct itself. Instead, excessive money supply is followed by increase in asset prices as a way to adjust for disequilibrium that exists. In short, the inherent instability of the fiat monetary system should be taken seriously. 
However, we contend that these results should not be taken as providing unequivocal support for the adoption of Gold Dinar. While the fiat monetary system contains weaknesses, the downsides of Gold Dinar also need to be assessed. In our case, we note that money supply reacts positively to accommodate expansion in real activities. This raises question on the viability of Gold Dinar. The reason is that Gold Dinar cannot be simply decreased or increased as needed. Indeed, the inability of money supply to meet the currency needs during the peak times of the classical gold standard resulted in deflation shocks and crises. The arguments for the Gold Dinar are further weakened when the issues of money supply controllability, policy independence, and propagation of deflation shocks across countries under the gold standard are considered.

\section{References}

Bank Negara Malaysia (various issues) Monthly Statistical Bulletin, Kuala Lumpur: BNM.

Barro, R.J. (1979) "Money and the Price under the Gold Standard", The Economic Journal, 89: 13-33. Bernstein, P.L. (2000) The Power of Gold, John Wiley, (n.p.).

Bernstein, E.M. (1981) "Perils of the Gold Standard", Challenge, November-December, 58-62.

Bordo, M.D. (1998) "Monetary Regimes and Economic Performance: Lessons from History", in G. Wood (ed.) Money, Prices and the Real Economy, Edward Elgar: Cheltenham, Chapter 4.

Bordo, M.D., Choudhri, E.U. and Schwartz, A.J. (2002) "Was Expansionary Monetary Policy Feasible during the Great Contraction? An Examination of the Gold Standard Constraint", Explorations in Economic History, 39: 1-28.

Choudhury, M.A. (2004) "Micro-Money and Real Economy Relationship in the 100 Per Cent Reserve Requirement Monetary System", Review of Islamic Economics, 8: 35-54.

Engle, R.F. and Granger, C.W.J. (1987) "Co-Integration and Error Correction: Representation, Estimation and Testing", Econometrica, 55(2): 251-276.

Haneef, M.A. and Barakat, E.R. (2002) "Gold and Silver as Money: A Preliminary Survey of Fiqhi Opinions and Their Implications", Proceedings of 2002 International Conference on Stable and Just Global Monetary System, 19-20 August 2002, Kuala Lumpur, Malaysia, pp.139-149.

Johansen, S. (1988) "Statistical Analysis of Cointegration Vectors", Journal of Economic Dynamics and Control, 12: 231-254.

Johansen, S. and Juselius, K. (1990) "Maximum Likelihood Estimation and Inference on Cointegration: with Applications to the Demand for Money", Oxford Bulletin of Economics and Statistics, 52(2): 169-210.

Kydland, F.E. and Wynne, M.A. (2002) "Alternative Monetary Constitutions and the Quest for Price Stability", Federal Reserve Bank of Dallas Economic and Financial Policy Review, 1(1): 1-19.

Meera, A.K.M. and Aziz, H.A. (2002) "The Islamic Gold Dinar: Socio-economic Perspectives", in Proceedings of 2002 International Conference on Stable and Just Global Monetary System, 19-20 August 2002, Kuala Lumpur, Malaysia, pp. 151-175.

Mishkin, F.S. (1997) The Economics of Money, Banking, and Financial Markets, $5^{\text {th }}$ Edition, Reading Addison-Wesley.

Mishkin, F.S. and Eakins, S.G. (2003) Financial Markets and Institutions, $4^{\text {th }}$ Edition, Boston Addison-Wesley.

Selover, D.D. and Round, D.K. (1996) "Business Cycle Transmission and Interdependence between Japan and Australia", Journal of Asian Economics, 7(4): 569-602.

Sims, C. (1980) "Comparison of Interwar and Postwar Business Cycles: Monetarism Reconsidered", American Economic Review: Papers and Proceedings, 70: 250-257.

Vadillo, U.I. (2002) "The Architecture of the Gold Dinar Economy: An Academic Perspective," in Proceedings of 2002 International Conference on Stable and Just Global Monetary System, 19-20 August 2002, Kuala Lumpur, Malaysia, pp. 335-360. 
الدينامكية النقدية و الدينار الذهبي: - منظور بتريي

$$
\begin{aligned}
& \text { منصور إبراهيم } \\
& \text { أستاذ قسم الاقتصاد } \\
& \text { الجامعة الإملامية الدولية بماليزيا }
\end{aligned}
$$

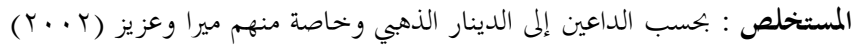

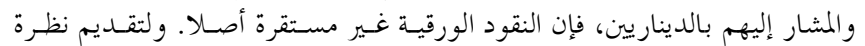

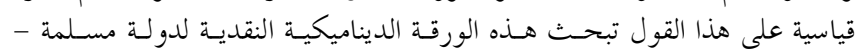

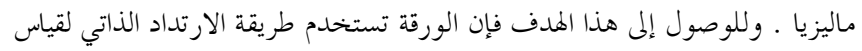

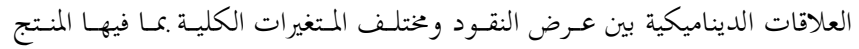

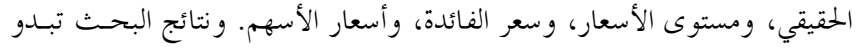
و كأنها تدعم رأي الديناريين.

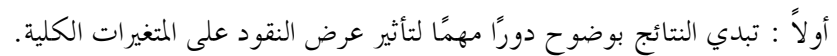

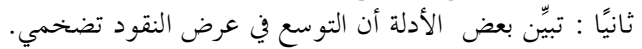
وأخيرًا : تفاعل عرض النقود وسعر الأدلة أنقائدة وأسعار الأسهم غير داعم للاستقرار.

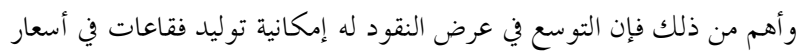

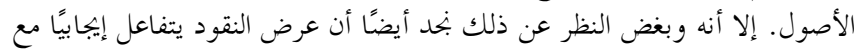

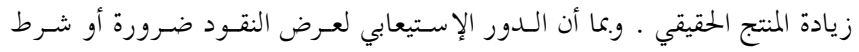

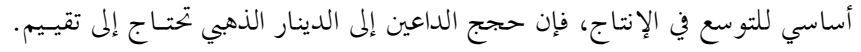

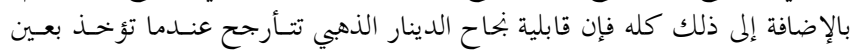

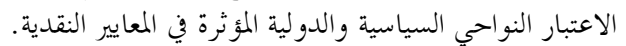

